\title{
Inhibitory effect of oleanolic acid on non-enzymatic glycation and glycometabolism in insulin resistant HepG2 cells
}

\author{
Z.K. Xie, S.Y. Yu, M. He, S.X. Yu, H.F. Xiao* (1) and Y.D. Song
}

School of Agricultural Engineering and Food Science, Shandong University of Technology, Zibo, Shandong, 255049, China

\section{ORIGINAL RESEARCH PAPER}

Received: July 9, 2020 • Accepted: October 8, 2020

Published online: February 12, 2021

(C) 2020 Akadémiai Kiadó, Budapest

\section{ABSTRACT}

In this paper, we studied the inhibitory effect of oleanolic acid (OA) on non-enzymatic glycosylation and the improvement of glycometabolism in insulin resistant (IR) human liver tumour (HepG2) cells. The antiglycosylation activity of OA was determined by bovine serum albumin (BSA) fructose model. The results showed that OA moderately inhibited the formation of the intermediates of non-enzymatic glycosylation, fructosamine and $\alpha$-dicarbonyl compounds, and strongly inhibited the formation of advanced glycation end products (AGEs). In addition, we analysed the effect of OA on glycometabolism induced by palmitic acid (PA) in HepG2 cells. The results showed that OA had almost no impact on HepG2 cell viability at concentrations lower than $30 \mu \mathrm{M}$. With the increase of OA concentration, glucose production in IR HepG2 cells decreased, while glycogen content increased. Meanwhile, OA has a significant inhibitory effect on reactive oxygen species (ROS) levels in IR-HepG2 cells. Those results suggested that OA could be a promising natural blood glucose decreasing substance in the pharmaceutical and functional food industries.

\section{KEYWORDS}

oleanolic acid, non-enzymatic glycation, insulin resistance, HepG2 cells

\footnotetext{
*Corresponding author. Tel.: +86 1836997 7602, E-mail: xiaohaifang@sdut.edu.cn
} 


\section{INTRODUCTION}

Diabetes (DM) is now a serious global problem that urgently needs to be studied in depth, as it is predicted by the World Health Organization that DM will become the seventh leading cause of death worldwide by 2030 (Ghosh et al., 2014). DM is a chronic metabolic disorder associated with a congenital (DM1) or acquired (DM2) inability to transport glucose from the bloodstream to cells (Gunawan-Puteri and Kawabata, 2010). Studies have shown that postprandial high blood glucose level is a major factor in the development and progression of DM2 (Dong et al., 2012). Besides, the increase of blood glucose level can lead to the acceleration of non-enzymatic glycation, which leads to the generation of advanced glycation end products (AGEs). Nonenzymatic glycation of protein occurs between reducing sugars and free amino acids, producing unstable Schiff base, which undergo rearrangement to early glycation Amadori-adducts such as fructosamine, and then further degraded into $\alpha$-dicarbonyl compounds, such as methylglyoxal, glyoxal and 3-deoxyglucose, and finally produces stable and irreversible AGEs by oxidation, dehydration and cycling reaction (Wu et al., 2011). The previous studies found that AGEs were associated with diabetic complications, such as hyperglycaemia, diabetic heart disease, diabetic ketoacidosis, or nonketotic hyperosmolar coma (Hwang et al., 2017). Thus, glycaemic control is an effective and long-term therapy to reduce the risk of DM2 as well as cardiovascular and neurological complication (Yilmazer-Musa et al., 2012). Currently, the synthetic drug aminoguanidine (AG) is used as a common anti-glycosylating agent. However, AG can have nonspecific and potentially toxic effects. Therefore, recent research has focused on effective and safe natural anti-diabetes compounds, primarily phytochemicals derived from edible or medicinal plants for the prevention of diabetes and its complications (Zeng et al., 2019).

Several potent anti-diabetes compounds have been found in natural products, such as gymnemic acid, cichoric acid, and vitexin (Zhu et al., 2015; Li et al., 2019; Peng et al., 2020). OA is a pentacyclic triterpenoid found in many fruits and vegetables such as, olive leaves, grapes, mistletoe sprouts, and papaya. OA has been shown to have a wide range of pharmacological and biochemical effects, including anti-inflammatory, anti-hyperlipidaemia and hypoglycaemia effects (Amico et al., 2009). In addition, OA has been shown to inhibit the activity of $\alpha$-glucosidase, which restricts intestinal glucose absorption (Hou et al., 2009), and protein tyrosine phosphatase $1 \mathrm{~B}$, which is a key factor in the negative regulation of the insulin pathway and a promising target for the treatment of DM and obesity (Zhang et al., 2008). Judging from the current literatures, the effects of OA on anti-glycosylation activity remain poorly understood.

In this study, the effects of OA on anti-glycosylation and glycometabolism of IR-HepG2 cells were measured. The BSA-fructose model was used to evaluate the inhibition of OA on fructosamine, $\alpha$-dicarbonyl compounds, and fluorescence AGEs in the process of non-enzymatic glycosylation. Besides, glucose production, glycogen content, and ROS levels of IR HepG2 cells treated with OA were also measured.

\section{MATERIALS AND METHODS}

\subsection{Materials and reagents}

OA (purity of 96\%) was obtained from Shanghai Yuanye Biological Technologyy Co., Ltd. (Shanghai, China). Girard-T reagent (purity of 98\%), PA (purity $>99 \%$ ), and fructose were 
purchased from Aladdin Chemistry Co. (Shanghai, China). BSA and dimethyl sulfoxide (DMSO) was obtained from Sigma (NY, USA). AG and nitroblue tetrazolium (NBT) were purchased from Macklin Biochemical Co., Ltd. (Shanghai, China). The human hepatoblastoma cell line (HepG2) was obtained from the Cell Bank of the Institute of Biochemistry and Cell Biology, Chinese Academy of Sciences (Shanghai, China). DMEM medium, foetal bovine serum (FBS), and penicillin-streptomycin (PS) were obtained from Gibco (NY, USA). Thiazolyl blue tetrazolium bromide (MTT) was obtained from Saiguo Biotechnology Co., Ltd. (Guangzhou, China). Other reagents were of analytical grade. Ultrapure water was used for the experiments.

\subsection{Determination of fructosamine concentration}

The inhibition effect of OA on fructosamine formation was studied using the BSA-fructose model (Wang et al., 2011). In the potassium phosphate buffer ( $\mathrm{pH} 7.4,0.2 \mathrm{M}$ ), BSA $\left(20 \mathrm{mg} \mathrm{mL}^{-1}\right)$, and fructose $(0.5 \mathrm{M})$ were incubated at $50{ }^{\circ} \mathrm{C}$ for $24 \mathrm{~h}$ in the absence (control) or presence (test sample) of OA at different concentrations $(0.10,0.20,0.50$ and $1.00 \mathrm{mM})$. After incubation, the $40 \mu \mathrm{L}$ reaction mixture was mixed with $1.6 \mathrm{~mL} \mathrm{NBT}(0.3 \mathrm{mM}$, dissolved in $100 \mathrm{mM}$ sodium carbonate buffer, $\mathrm{pH}$ 10.35) and $320 \mu \mathrm{L}$ ultrapure water and incubated at room temperature of $25{ }^{\circ} \mathrm{C}$ for $15 \mathrm{~min}$. Fructosamine can reduce NBT to $\mathrm{NBT}^{+}$. Further disproportionation produces a highly coloured dirty dye, which has strong ultraviolet absorption at $530 \mathrm{~nm}$, so fructosamine can be quantify by absorbance measurement at $530 \mathrm{~nm}$. AG was used as a positive control for this assay.

\subsection{Determination of $\alpha$-dicarbonyl compounds}

The inhibitory effect of OA on middle stage glycation was evaluated by quantitative study of $\alpha$-dicarbonyl compounds (Wang et al., 2011). It is reported that Girard-T reagent can react with aldehydes or ketones containing $\alpha$-dicarbonyl under weak acidic or weak basic conditions, and its addition products have strong absorption in the ultraviolet region. Therefore, the content of $\alpha$-dicarbonyl compounds can be evaluated according to the absorbance value of the reaction solution in the ultraviolet region. Briefly, the $40 \mu \mathrm{L}$ above-described incubated solution, $160 \mu \mathrm{L}$ ultrapure water, $100 \mu \mathrm{L}$ of $500 \mathrm{mM}$ Girard-T reagent (soluble in ultrapure water) were mixed with $1.7 \mathrm{~mL}$ sodium formate $(500 \mathrm{mM}, \mathrm{pH} 2.9)$, incubated at $25{ }^{\circ} \mathrm{C}$ for $1 \mathrm{~h}$, and then the absorbance of the mixture was determined at $290 \mathrm{~nm}$ (Wells-Knecht et al., 1995).

\subsection{In vitro glycation assay}

The determination of AGEs was performed using a published procedure (Lee et al., 2015). Briefly, the BSA-fructose-water and BSA-fructose-AG/OA reaction systems were incubated at $50{ }^{\circ} \mathrm{C}$ for $24 \mathrm{~h}$. After incubation, the fluorescence intensity of the mixture at $400-600 \mathrm{~nm}$ was recorded at the emission wavelength of $453 \mathrm{~nm}$ with the excitation wavelength of $360 \mathrm{~nm}$. The fluorescent AGEs inhibition rate was calculated using the following formula (Zeng et al., 2019):

$$
\text { Relative fluorescent activity }(\%)=\frac{A_{1}-A_{2}}{A_{1}} \times 100 \%
$$

where $A_{1}$ is the fluorescence of control. $A_{2}$ is the fluorescence of test sample. 


\subsection{Cell culture}

HepG2 cells were cultured in complete medium (DMEM containing $4.5 \mathrm{mM}$ glucose, 10\% FBS, and $1 \% \mathrm{PS}$ ) at $37{ }^{\circ} \mathrm{C}$ in a humidified atmosphere containing $5 \% \mathrm{CO}_{2}$. After reaching $80-95 \%$ confluence, cells $\left(1 \times 10^{5}\right.$ cells $\left./ \mathrm{mL}\right)$ were seeded in 96 -well microtiter plates prior to experiments.

\subsection{MTT assay}

The range of nontoxic OA concentrations cells was evaluated using MTT assay according to the method described by $\mathrm{Li}$ et al. (Li et al., 2019). In this assay, HepG2 cells were seeded in 96-well plates at a density of $1 \times 10^{5}$ per well and incubated for $24 \mathrm{~h}$. After aspiration of the culture medium, new serum-free medium containing serial concentrations $(0,20,30,40,50,60,70$ and $80 \mu \mathrm{M})$ of $\mathrm{OA}$ in a volume of $150 \mu \mathrm{L}$ was added and the plates were incubated for a further $24 \mathrm{~h}$ prior to the addition of $20 \mu \mathrm{L}$ of MTT labelling reagent. After incubation for $4 \mathrm{~h}$, the MTT containing medium was discarded, and the metabolised product of MTT (blue-violet crystals) was dissolved in DMSO. The absorbance of the samples at $570 \mathrm{~nm}$ was measured to determine effects on cell viability or cytotoxicity. The cell viability was calculated by the following formula:

$$
\text { The cell viability }(\%)=\frac{\text { Absorbance of experimental group }}{\text { Absorbance of blank control group }} \times 100 \%
$$

\subsection{Glucose production analysis}

Glucose production analysis was performed based on a previously reported method (Gu et al., 2015). Briefly, HepG2 cells $\left(1 \times 10^{5}\right.$ cells/well $)$ were seeded in 6 -well plates and cultured in normal DMEM as a normal control group (N), and the model control group (Mod) and treatment groups were maintained in DMEM containing $0.6 \mathrm{mM}$ PA for $24 \mathrm{~h}$. In the Mod and N groups, DMEM was used to replace the medium. In the treatment groups, the medium was replaced with DMEM mixed with different concentrations $(5,15$ and $25 \mu \mathrm{M})$ of OA and incubated for $24 \mathrm{~h}$. Then, the cells were cultured in glucose-free DMEM added with $5 \mathrm{mM}$ glycine, valine, alanine, lactate, and pyruvate for $2 \mathrm{~h}$. The culture solution was collected and examined using a glucose oxidase method kit (Shanghai Rongsheng, Shanghai, China).

\subsection{Glycogen content determination}

Glycogen content analysis was performed according to Gupta and Khandelwal (2004). HepG2 cells were seeded into 6-well plates at a concentration of $1 \times 10^{5}$ cells $/ \mathrm{mL}$. After model establishment, the cells were treated with different concentrations of OA. Then, the cells were washed three times with phosphate buffer solution (PBS) and collected by centrifugation (4,000 r.p.m. for $15 \mathrm{~min}, 4^{\circ} \mathrm{C}$ ) for estimation of the glycogen content using a commercial kit (Solarbio, Beijing, China).

\subsection{ROS level estimation}

In this experiment, ROS levels were analysed according to the method described by Tian et al. (2006) with some modifications. Briefly, HepG2 cells $\left(1 \times 10^{5}\right.$ cells/well $)$ were incubated in 96-well plates, and after the model establishment and OA treatment, the medium was removed and washed three times with PBS. The treated cells were cultured at $37^{\circ} \mathrm{C}$ in DMEM containing $10 \mu \mathrm{M}$ $2^{\prime}, 7^{\prime}$-dichlorodihydrofluorescein diacetate (DCFH-DA) (Beyotime, Shanghai, China) for $30 \mathrm{~min}$. 
ROS levels were detected by a fluorescence plate reader (Thermo Fisher, Shanghai, China) at $488 \mathrm{~nm}$ for excitation and $525 \mathrm{~nm}$ for emission. The ROS levels were indicated by percentages relative to the fluorescence strength of the untreated normal cells (100\%). Images of ROS levels were obtained using a Nikon ELIPSE Ti-S fluorescence microscope (Nikon, Tokyo, Japan).

\subsection{Statistical analysis}

The results were expressed as the mean values \pm standard deviations. One-way analysis of variance (ANOVA) was implemented by using Origin 8.0 followed by multiple tests in order to determine the significant difference at $P<0.05$.

\section{RESULTS AND DISCUSSION}

\subsection{Effect of $O A$ on fructosamine production}

As shown in Fig. 1, OA exhibited a certain inhibitory effect on fructosamine with the inhibition rates of $6.02,9.30,22.71$ and $34.44 \%$ when the concentrations of OA were $0.1,0.2,0.5$ and 1.0 $\mathrm{mM}$, respectively, while the inhibition rates of AG (positive control) were 13.42 and $16.90 \%$ with the AG concentrations at 1 and $2 \mathrm{mM}$, respectively. Therefore, OA was superior to AG in inhibiting fructosamine formation. The inhibitory effect of OA on the formation of fructosamine may be attributed to the fact that the chelation of metal ions by OA reduces the oxidation of glycosylated proteins, thus inhibiting the formation of amadori products.

\subsection{Effect of $\mathrm{OA}$ on the formation of $\alpha$-dicarbonyl compounds}

As shown in Fig. 2, with the increase of OA concentration, the inhibition rate was on the rise. When the OA concentration was 0.5 and $1.0 \mathrm{mM}$, the inhibition rates of $\mathrm{OA}$ on the generation

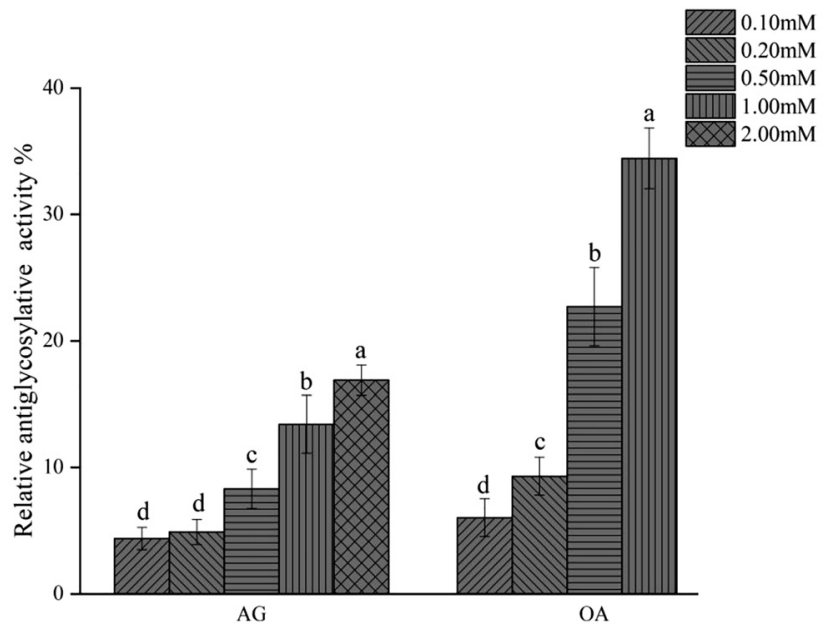

Fig. 1. Inhibitory activities of OA and AG on the generation of fructosamine. Different letters of the same group denote significant differences $(P<0.05)$ at different concentrations. Similarly, hereinafter 


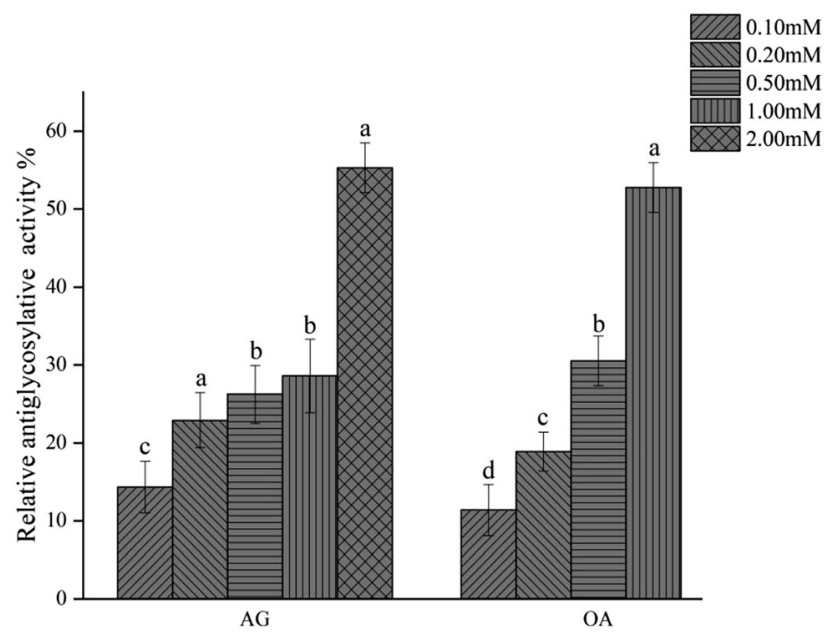

Fig. 2. Inhibitory activities of $\mathrm{OA}$ and $\mathrm{AG}$ on the generation of $\alpha$-dicarbonyl compounds

of $\alpha$-dicarbonyl compounds were 30.49 and $52.75 \%$, respectively. Also, the inhibition rates were higher than that of AG at the same concentration. The inhibitory effect of OA on the production of $\alpha$-dicarbonyl compounds was stronger than that of fructosamine, which may be due to the chelation of metal ions in the formation of fructosamine and the scavenging effect of OA on free radicals, thus reducing the conversion of fructosamine to the synthesis of $\alpha$-dicarbonyl compounds (Russo et al., 2002).

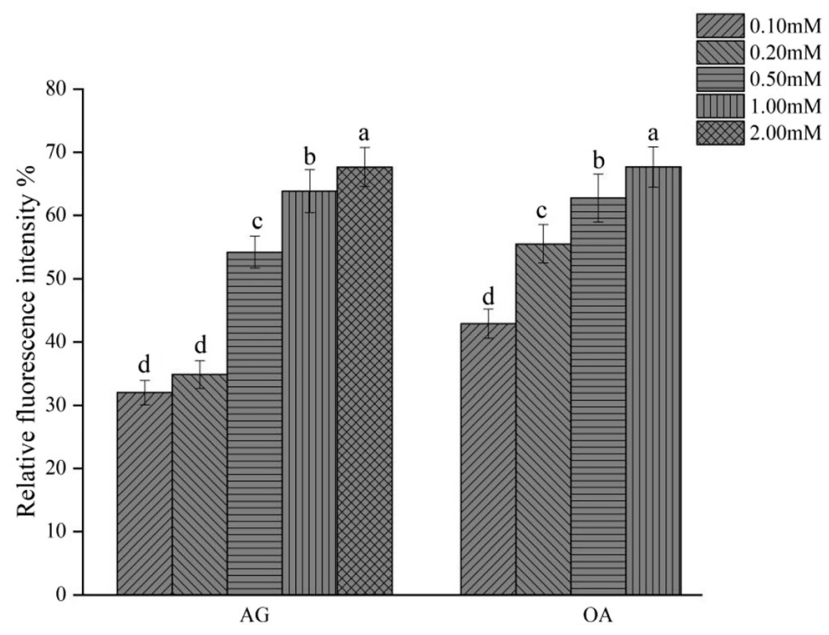

Fig. 3. Inhibitory activities of $\mathrm{OA}$ and $\mathrm{AG}$ on the generation of AGEs 


\subsection{Inhibition of $O A$ on fluorescence AGEs}

Compared with the positive control group, OA effectively inhibited the production of fluorescent AGEs (Fig. 3), and the inhibition rate positively correlated with OA concentration. When the concentration was $0.2 \mathrm{mM}$, OA had the strongest inhibitory effect on AGEs, with an
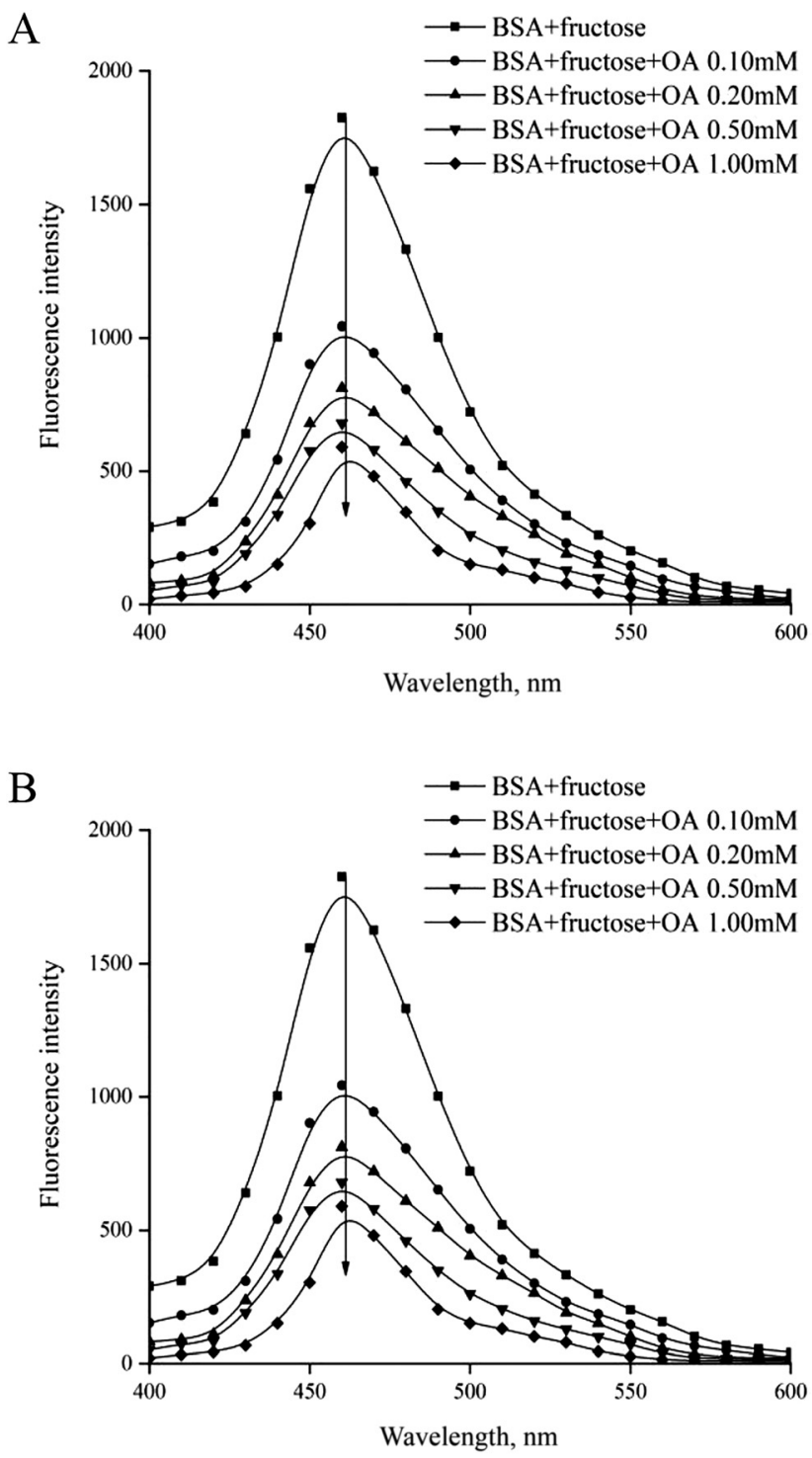

Fig. 4. (A): The fluorescence spectra of AGEs in the presence of increasing concentrations of AG. (B): The fluorescence spectra of AGEs in the presence of increasing concentrations of OA 
inhibitory rate of $67.67 \%$, while the inhibitory rate of AG was $63.82 \%$ under the same concentration. Obviously, the results showed that the anti-glycosylation activity of OA was better than that of the positive control. In addition, it can be inferred from the above results that the inhibition ability of $\mathrm{OA}$ in the late stage was significantly stronger than in the early and middle stages, which may be mainly due to blockage of cross-linking of proteins and prevention of the formation of AGE in the late stage (Wu and Yen, 2005).

As shown in Fig. 4, in the BSA-fructose-AG/OA mixture, incubated at $50{ }^{\circ} \mathrm{C}$ for $24 \mathrm{~h}$, fluorescent AGEs were generated, since the fluorescence intensity excited at $360 \mathrm{~nm}$ (reflected fluorescent AGEs) increased dramatically (black lines). Upon the addition of OA and AG, the fluorescence intensity decreased with a distinct red shifts of maximum emission wavelength (from 459 to $463 \mathrm{~nm}$ and from 455 to $462 \mathrm{~nm}$, respectively), indicating that the polarity around fluorophores increased with the addition of OA. OA was found to inhibit the generation of AGEs in vitro, suggesting that $\mathrm{OA}$ is a potential antidiabetic compound for prevention of hyperglycaemia induced damage.

\subsection{Cytotoxicity of $O A$ treatment to HepG2 cells}

It is well known that high levels of the drug can inhibit cell activities and induces apoptosis (Nie et al., 2017). To determine the optimal concentration of OA used in this study, we evaluated the toxicity of OA to HepG2 cells. As shown in Fig. 5, OA at concentrations exceeding $40 \mu \mathrm{M}$ reduced cell viability. The viability of HepG2 cells was higher than 95\% at OA concentration lower than $30 \mu \mathrm{M}$, indicating that $\mathrm{OA}$ at the concentrations below $30 \mu \mathrm{M}$ is suitable for use in bioactivity assays. Based on these results, OA was used at 5, 15 and $25 \mu \mathrm{M}$ in the subsequent experiments.

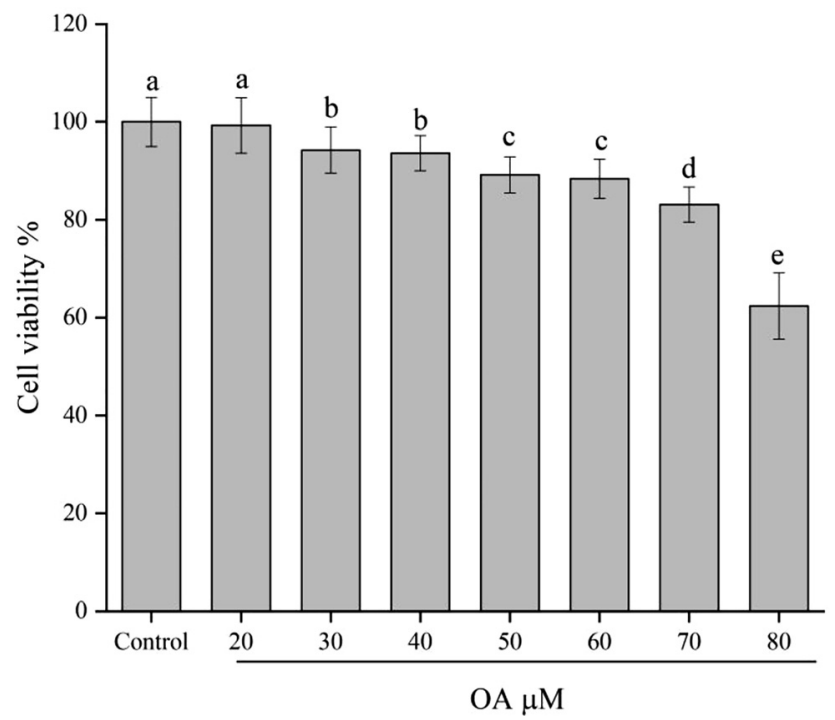

Fig. 5. HepG2 cells treated with different concentrations of OA for $24 \mathrm{~h}$ and analysed by MTT assays 


\subsection{OA regulates glucose production in IR HepG2 cells}

IR highly correlated with extracellular glucose consumption due to the decrease of the sensitivity of insulin receptors. According to Fig. 6A, after PA induction, glucose production increased

A

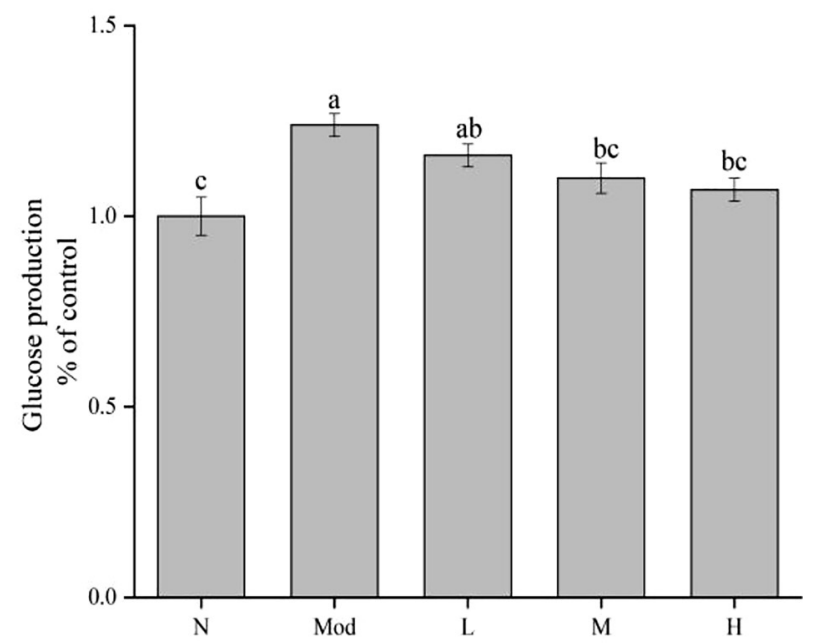

B

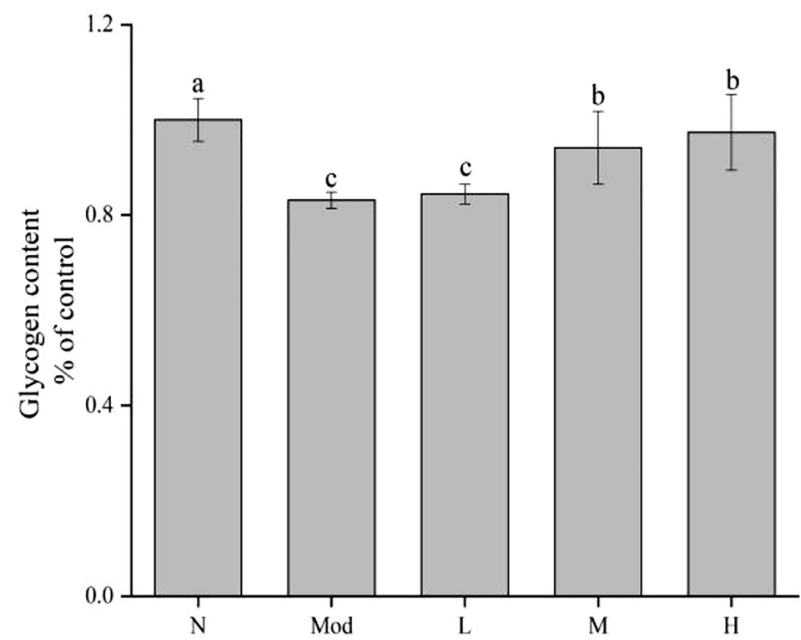

Fig. 6. (A) Effect of OA on glucose production in IR-HepG2 cells. (B) Effect of OA on glycogen content in IR-HepG2 cells. N: normal control group; Mod: model control group; L: OA-5.0 $\mu \mathrm{M}$; M: OA-15.0 $\mu \mathrm{M}$; H: GA-25.0 $\mu$ M. Similarly, hereinafter 
significantly, which was consistent with previous studies (Liu et al., 2019). Glucose production decreased in the OA treatment groups compared to the model group. These data suggested that OA was able to improve extracellular glucose production in IR HepG2 cells. Li et al. (2019) found that gymnemic acid could increase glucose production in PA-induced HepG2 cells.

\subsection{OA regulates glycogen content in IR HepG2 cells}

In order to investigate intracellular glycogen content changes of OA treated HepG2 cell, intracellular glycogen was extracted for detection. As Fig. 6B shows, compared with normal group, the intracellular glycogen of PA group decreased, which showed the effectiveness of the model (Li et al., 2019). With the increase of OA concentration, the content of glycogen increased gradually. The results suggested that OA enhanced synthesis of intracellular glycogen at $24 \mathrm{~h}$, so OA ameliorated insulin resistance of model control group through the pathway of enhancing synthesis of intracellular glycogen. Similarly, other active substances, such as mogroside and gymnemic acid, increased the glycogen content of IR HepG2 cells (Liu et al., 2019).

\subsection{OA regulates ROS level in IR HepG2 cells}

DCFH-DA could be hydrolysed into DCFH by intracellular esterase, and then the active oxygen in the cells oxidises the non-fluorescent DCFH to generate fluorescent DCF. As a consequence, the fluorescence of DCF is the standard for judging the levels of ROS in cells (Yang et al., 2019). It was found that after PA induction, the level of ROS in cells increased significantly (Fig. 7). Diverse concentrations of $\mathrm{OA}$ treatment decreased the intensity of green fluorescence in a dosage dependent pattern (Fig. 8), which was consistent with the quantitative result of ROS level measured by a multi-function microplate reader. Compared with untreated normal cells, the intracellular ROS levels of HepG2 cells treated with different concentrations of OA $(5,15$ and 25 $\mu \mathrm{M})$ for $24 \mathrm{~h}$ signally increased to $143.80,135.30$ and $113.52 \%$, respectively. Tian et al. (2006)

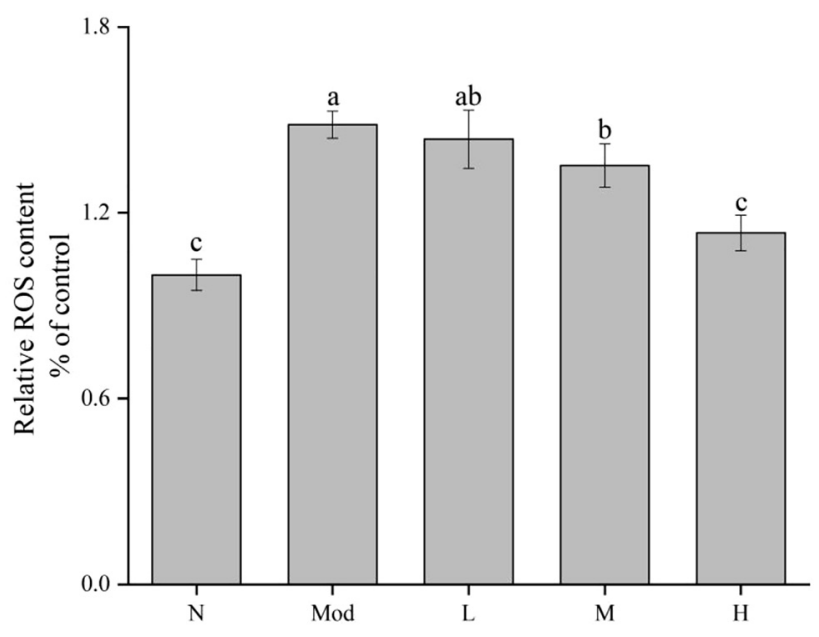

Fig. 7. Column bar graph of the ROS levels in HepG2 cells 

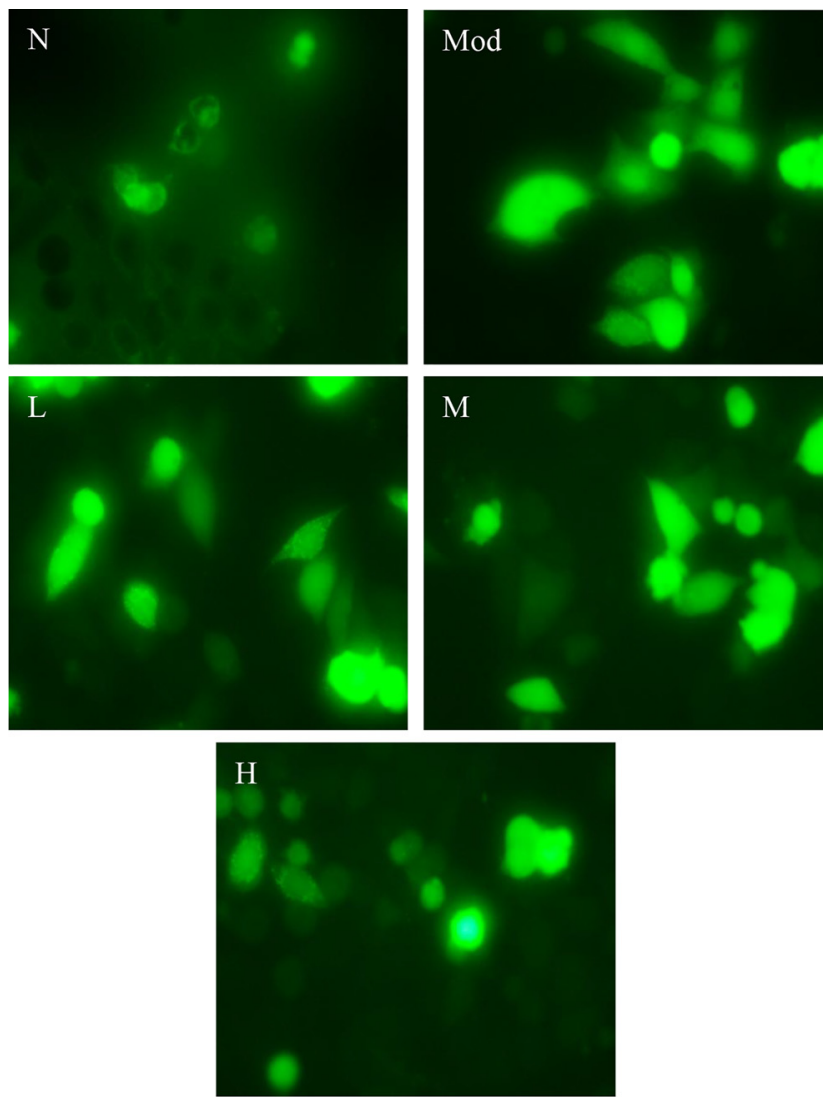

Fig. 8. The ROS level determined using DCFH-DA probe on fluorescence microscope

also found that catalpol dose-dependently attenuated lipopolysaccharide induced ROS production in microglia-enriched cultures.

\section{CONCLUSIONS}

In summary, anti-glycosylation activity of OA at the early, middle, and late stages of AGE formation and the regulation of glucose metabolism in IR-HepG2 cells were evaluated. Results suggested that OA moderately inhibited the formation of fructosamine and $\alpha$-dicarbonyl compounds at the studied concentrations, and strongly suppressed the generation of AGEs. In addition, OA can effectively suppress glucose production, improve glycogen content, and reduce ROS levels in IR HepG2 cells in a dose-dependent manner. This study provides new information on how OA regulates glycometabolism in insulin resistant HepG2 cells and glycation inhibitors, although still more experiments are needed in vitro and in vivo to elucidate. 


\section{ABREVIATIONS}

$\begin{array}{ll}\text { OA } & \text { Oleanolic acid } \\ \text { IR } & \text { Insulin resistant } \\ \text { HepG2 } & \text { Human liver tumour } \\ \text { BSA } & \text { Bovine serum albumin } \\ \text { AGEs } & \text { Advanced glycation end products } \\ \text { PA } & \text { Palmitic acid } \\ \text { ROS } & \text { Reactive oxygen species } \\ \text { DCFH-DA } & 2^{\prime}, 7^{\prime} \text {-dichlorodihydrofluorescein diacetate } \\ \text { DM } & \text { Diabetes } \\ \text { AG } & \text { Aminoguanidine } \\ \text { FBS } & \text { Foetal bovine serum } \\ \text { PS } & \text { Penicillin-streptomycin } \\ \text { MTT } & \text { Thiazolyl blue tetrazolium bromide }\end{array}$

\section{ACKNOWLEDGEMENTS}

This work was supported by SDUT and Zibo City Integration Development Project (2017ZBXC004) and Shandong Provincial Natural Science Foundation, China (No. ZR2014CQ002). Therefore, we are grateful for the funding and support of this research.

\section{REFERENCES}

Amico, V., Barresi, V., Chillemi, R., Condorelli, D.F., and Tringali, C. (2009). Bioassay-guided isolation of antiproliferative compounds from grape (Vitis vinifera) Stems. Natural Product Communications, 4: $27-34$.

Dong, H.-Q., Li, M., Zhu, F., Liu, F.-L., and Huang, J.-B. (2012). Inhibitory potential of trilobatin from Lithocarpus polystachyus Rehd against $\alpha$-glucosidase and $\alpha$-amylase linked to type 2 diabetes. Food Chemistry, 130: 261-266.

Ghosh, S., More, P., Derle, A., Patil, A.B., Markad, P., Asok, A., Kumbhar, N., Shaikh, M.L., Ramanamurthy, B., Shinde, V.S., Dhavale, D.D., and Chopade, B.A. (2014). Diosgenin from Dioscorea bulbifera: novel hit for treatment of type II diabetes mellitus with inhibitory activity against $\alpha$-amylase and $\alpha$-glucosidase. Plos One, 9: e106039.

Gu, J.-F., Zheng, Z.-Y., Yuan, J.-R., Zhao, B.-J., Wang, C.-F., Zhang, L., Xu, Q.-Y., Yin, G.-W., Feng, L., and Jia, X.-B. (2015). Comparison on hypoglycemic and antioxidant activities of the fresh and dried Portulaca oleracea L. in insulin-resistant HepG2 cells and streptozotocin-induced C57BL/6J diabetic mice. Journal of Ethnopharmacology, 161: 214-223.

Gunawan-Puteri, M.D.P.T. and Kawabata, J. (2010). Novel $\alpha$-glucosidase inhibitors from Macaranga tanarius leaves. Food Chemistry, 123: 384-389.

Gupta, D. and Khandelwal, R.L. (2004). Modulation of insulin effects on phosphorylation of protein kinase $\mathrm{B}$ and glycogen synthesis by tumor necrosis factor- $\alpha$ in HepG2 cells. Biochimica et Biophysica Acta, 1671: 51-58. 
Hou, W., Li, Y., Zhang, Q., Wei, X., Peng, A., Chen, L., and Wei, Y. (2009). Triterpene acids isolated from Lagerstroemia speciosa leaves as $\alpha$-glucosidase inhibitors. Phytotherapy Research, 23: 614-618.

Hwang, S.H., Wang, Z., and Lim, S.S. (2017). Chemo-enzymatic synthesis of vinyl and L-ascorbyl phenolates and their inhibitory effects on advanced glycation end products. Food Chemistry, 214: 726-735.

Lee, C.C., Lee, B.H., and Lai, Y.J. (2015). Antioxidation and antiglycation of Fagopyrum tataricum ethanol extract. Journal of Food Science and Technology, 52: 1110-1116.

Li, Y., Sun, M., Liu, Y., Liang, J., Wang, T., and Zhang, Z. (2019). Gymnemic acid alleviates type 2 diabetes mellitus and suppresses endoplasmic reticulum stress in vivo and in vitro. Journal of Agricultural and Food Chemistry, 67: 3662-3669.

Liu, X., Zhang, J., Li, Y., Sun, L., Xiao, Y., Gao, W., and Zhang, Z. (2019). Mogroside derivatives exert hypoglycemics effects by decreasing blood glucose level in HepG2 cells and alleviates insulin resistance in T2DM rats. Journal of Functional Foods, 63: 103566.

Nie, J., Chang, Y., Li, Y., Zhou, Y., Qin, J., Sun, Z., and Li, H. (2017). Caffeic acid phenethyl ester (propolis extract) ameliorates insulin resistance by inhibiting JNK and NF- $\kappa$ B inflammatory pathways in diabetic mice and HepG2 cell models. Journal of Agricultural and Food Chemistry, 65: 9041-9053.

Peng, Y., Gan, R., Li, H., Yang, M., McClements, D.J., Gao, R., and Sun, Q. (2020). Absorption, metabolism, and bioactivity of vitexin: recent advances in understanding the efficacy of an important nutraceutical. Critical Reviews in Food Science and Nutrition, 1-16.

Russo, A., Longo, R., and Vanella, A. (2002). Antioxidant activity of propolis: role of caffeic acid phenethyl ester and galangin. Fitoterapia, 73: S21-S29.

Tian, Y.Y., An, L.J., Jiang, L., Duan, Y.L., Chen, J., and Jiang, B. (2006). Catalpol protects dopaminergic neurons from LPS-induced neurotoxicity in mesencephalic neuron-glia cultures. Life Sciences, 80: 193-199.

Wang, S.H., Chang, J.C., Pokkaew, R., Lee, J.F., and Chiou, R.Y. (2011). Modified fast procedure for the detection and screening of antiglycative phytochemicals. Journal of Agricultural and Food Chemistry, 59: 6906-6912.

Wells-Knecht, K.J., Zyzak, D.V., Litchfield, J.E., Thorpe, S.R., and Baynes, J.W. (1995). Identification of glyoxal and arabinose as intermediates in the autoxidative modification of proteins by glucose. Biochemistry, 34: 3702-3709.

Wu, C.-H., Huang, S.-M., Lin, J.-A., and Yen, G.-C. (2011). Inhibition of advanced glycation endproduct formation by foodstuffs. Food \& Function, 2: 224-234.

$\mathrm{Wu}, \mathrm{C}$. and Yen, G. (2005). Inhibitory effect of naturally occurring flavonoids on the formation of advanced glycation endproducts. Journal of Agricultural and Food Chemistry, 53(8): 3167-3173.

Yang, S., Xiao, H., Yu, S., Xie, Z., Yu, S., and Song, Y. (2019). Inhibition effect of walnut leaf polysaccharide on HepG2 Cells in vitro. American Journal of Biochemistry and Biotechnology, 15: 179-189.

Yilmazer-Musa, M., Griffith, A. M., Michels, A.J., Schneider, E., and Frei, B. (2012). Grape seed and tea extracts and catechin 3-gallates are potent inhibitors of alpha-amylase and $\alpha$-glucosidase activity. Journal of Agricultural and Food Chemistry, 60: 8924-8929.

Zeng, L., Ding, H., Hu, X., Zhang, G., and Gong, D. (2019). Galangin inhibits $\alpha$-glucosidase activity and formation of non-enzymatic glycation products. Food Chemistry, 271: 70-79.

Zhang, Y.N., Zhang, W., Hong, D., Shi, L., Shen, Q., Li, J.-Y., Li, J., and Hu, L.H. (2008). Oleanolic acid and its derivatives: new inhibitor of protein tyrosine phosphatase 1B with cellular activities. Bioorganic \& Medicinal Chemistry, 16: 8697-8705.

Zhu, D., Wang, Y., Du, Q., Liu, Z., and Liu, X. (2015). Cichoric acid reverses insulin resistance and suppresses inflammatory responses in the glucosamine-induced HepG2 cells. Journal of Agricultural and Food Chemistry, 63: 10903-10913. 